\title{
Os Annales e nós
}

\author{
The Annales and us
}

ROIZ, Diogo da Silva; SANTOS, Jonas Rafael.Astransferênciasculturais na historiografia brasileira: leituras e apropriações do movimento dos Annales no Brasil. Jundiaí: Paco Editorial, 2012, 296 p.

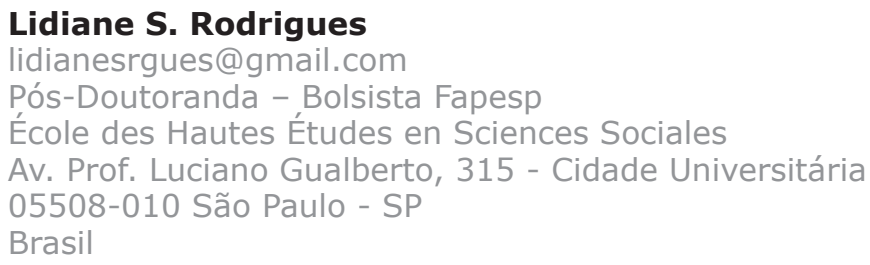

Palavras-chave

Annales; Historiografia; Universidade de São Paulo.

Keywords: Annales School

192

Annales; Historiography; Universidade de São Paulo. 
O livro de Diogo da Silva Roiz e Jonas Rafael dos Santos, As transferências culturais na historiografia brasileira: leituras e apropriações do movimento dos Annales no Brasil, é parte do momento de efervescência que atravessa a área de estudos a que se liga. A história da historiografia tem suscitado interesse, adensado sua produção, diversificado seus eixos analíticos por meio da interdisciplinaridade e da abertura de seu leque temático: eis o cenário em que é publicado o livro.

Com a obra, os autores ambicionam tratar de uma dimensão relevante para a caracterização e compreensão da historiografia brasileira, particularmente aquela produzida no século XX no interior do sistema universitário: leituras e apropriações da produção da chamada "Escola dos Annales". O livro é composto por sete capítulos, um epílogo e um apêndice - além da apresentação de Helenice Rodrigues da Silva e do posfácio de Karina Anhenzini. Os autores contemplam volumosa bibliografia, além de valer-se de onze quadros e treze tabelas que sumarizam informações institucionais e dados quantitativos. Indiscutivelmente, trata-se de um levantamento laborioso.

No primeiro capítulo, "A invenção de uma tradição: 'A Escola dos Annales"', os autores situam historicamente os Annales, destacando a ambição do grupo em se opor à "escola metódica", "dita positivista" (ROIZ; SANTOS 2013, p. 38). Apresentam também algumas dificuldades envolvidas no emprego do termo "escola" e assinalam uma possível aproximação entre os Annales e o marxismo a partir da ideia de "busca da totalidade". No segundo capítulo, "A interpretação da 'História total' no pensamento de Fernand Paul Braudel entre 1949 e 1958", os autores apresentam a biografia desse historiador e seu interesse em dialogar com as ciências sociais. Elencam os alunos e professores brasileiros com que ele estabeleceu contato entre 1935-1937, quando era docente na recémcriada Faculdade de Filosofia, Letras e Ciências Humanas da Universidade de São Paulo (FFLCH-USP). Passando em revista algumas declarações e "histórias dos Annales", os autores indagam-se a respeito de disputas pelo poder no interior do grupo ligadas à sucessão geracional. No capítulo seguinte, "Limites e possibilidades de pesquisa entre a 'História das Mentalidades' e a 'Nova História Cultural'", essas duas modalidades historiográficas são situadas uma em relação à outra e ambas em relação ao marxismo e à História Política e Econômica a partir da perspectiva de seus praticantes. Já no quarto capítulo, "A recepção da 'Escola dos Annales' na Europa e nas Américas: algumas reflexões" encontra-se um bom balanço da bibliografia a respeito da história do grupo dos Annales. São contemplados os trabalhos que com mais frequência entram em tela quando se trata desse assunto, o que implica a realização de um levantamento exaustivo. Ousaria, porém, sugerir que há uma lacuna: a ausência de Gerard Noiriel, cuja perspectiva analítica a propósito dos padrões de carreira dos historiadores franceses poderia enriquecer a discussão (NOIRIEL 1990). No capítulo seguinte, "Os Annales no Brasil: institucionalização do ensino universitário de Geografia e História na Faculdade de Filosofia", encontra-se uma paciente descrição do currículo, das reformas curriculares, da organização do curso, das teses e orientações do curso em questão. As informações são extraídas dos Anuários que 
a instituição produzia em seus primeiros anos, da Revista de História, fundada por Eurípedes Simões de Paula em 1950 e de inventários de teses e dissertações defendidas. No sexto capítulo, denominado "Historiadores brasileiros e franceses: uma hipótese para a recepção da Escola dos Annales no Brasil", os autores apostam na centralidade das missões francesas de fundação da Universidade de São Paulo (nos setores de História e Geografia) para o entendimento da influência dos Annales na historiografia brasileira. Retomam - posto que já apresentado em capítulos anteriores - o histórico da instituição paulista e da Revista dos Annales - e procuram realizar esse propósito expondo a trajetória de um dos primeiros catedráticos brasileiros (Eurípedes Simões de Paula, 1910-1977), examinando (o número de) os autores estrangeiros presentes na Revista de História e apresentando os nomes dos catedráticos e de suas respectivas áreas. O último capítulo, "Da França para o Brasil: leituras e apropriações do Marxismo e da 'Nova História Cultural' num departamento de História", é dedicado à apresentação da trajetória de 15 professores do Departamento de História da Universidade Estadual Paulista (Unesp), do campus de Franca, procurando situá-los, como intelectuais "herdeiros do marxismo" e "estudiosos da cultura" que se vincularam à "nova história cultural" (ROIZ; SANTOS 2013, p. 203). Diante de um capítulo tão laborioso e paciente, que apresenta teses, memoriais, entrevistas, orientações, o ímpeto de fazer qualquer sugestão padeceria de constrangimento. No entanto, a entrevista realizada com Ivan Aparecido Manoel e transcrita no "Apêndice", sugere que os autores se mantiveram rentes à narrativa dos próprios professores, às suas categorias (auto)classificatórias, sem indagar interesses de ordem material e simbólica em operação na sua formulação. Por fim, quanto ao epílogo, o título, "Como os historiadores escrevem a(s) sua(s) história(s)", instiga a sugerir que seja enganoso. Talvez fosse o caso de intitulá-lo "como não escrevem a(s) sua(s) história(s)", não para diminuir ou desmerecer o trabalho, mas ao contrário. Os autores ponderam de modo maduro e corajoso - coisa rara, diga-se de passagem - o que não foi possível fazer, assinalam falhas e fazem sugestões para possíveis desenvolvimentos. Assim, acreditam ser necessário aprofundar mais a pesquisa a respeito da "tradição inventada" (ideia do primeiro capítulo); reclamam por mais estudos que sistematizem a produção da pós-graduação em História, a fim de dar suporte às análises; e assinalam que não se deve generalizar para o restante do país o que foi apresentado para o cenário paulista (ROIZ; SANTOS 2013, p. 238-239).

$\mathrm{Na}$ qualidade de pesquisadora interessada em pelo menos dois filões que pontilham os artigos - a saber, história da historiografia e circulação internacional das ideias -, teço sugestões com o objetivo de somar meus esforços aos dos autores, adotando como direção uma observação de Christophe Charle: a história social das disciplinas universitárias deve "não apenas reconstituir a relação entre as instituições, os homens e as obras, mas igualmente compreender as condições favoráveis ou desfavoráveis à inovação" (CHARLE 2003, p. 33).

O volume considerável de documentos e bibliografia reunido pelos autores é acionado no livro em pelo menos dois planos: o da organização institucional (currículos, disciplinas, regimentos) e o biográfico (trajetórias dos historiadores). 
Isso se evidencia, em particular, nos capítulos segundo e sexto, em que eles tentam articular tais dimensões para os casos de Fernand Braudel e Eurípedes Simões de Paula, respectivamente.

Assente que o regramento institucional em que os agentes se movimentam é decisivo para as possibilidades de sua produção, é imperativo se atentar para os artifícios que eles desenvolvem para contorná-lo. Isso porque o "estudo do controle das universidades pelo Estado, da descentralização universitária, ou do recrutamento dos administradores e dos professores", que se apoiasse primordialmente em "textos de regulamentação, seria tão enganoso quanto a pesquisa dos comportamentos religiosos que quisesse inferir dos textos canônicos a prática real dos crentes" (BOURDIEU 1979, p. 82). Sendo essa prática o que interessa à história da historiografia, alguém poderia perguntar inocentemente: em que isso incide na produção propriamente intelectual? Ora, essa é a jogada mais central dentre as estratégias da produção simbólica.

Os autores dedicam bastante atenção à dimensão legislativa da vida universitária, e isso é necessário, porém não em detrimento da vivência social articulada à análise das "obras" (teses, resenhas, textos programáticos). A paciente descrição da network de Eurípedes Simões de Paula - Eduardo D'Oliveira França, Sérgio Buarque de Holanda, Pedro Moacyr Campos (ROIZ; SANTOS 2013, p. 176-177) - não requereria investigar quem eram eles, quando jovens, quando se aproximaram e como chegaram a estabelecer os laços de solidariedade profissional em meio a rivalidades intelectuais? Indagar sobre tais nexos teria conduzido os autores a explorar um pouco mais a sociabilidade desses primeiros catedráticos da FFCL-USP, bem como o regime de importação de práticas intelectuais oriundas das Faculdades de Direito, pelas quais todos eles passaram. O fato de a FFCL-USP se apresentar como rival das escolas "tradicionais" (Medicina, Direito, Engenharia) instiga a hipótese de que ou essa é uma invenção construída a posteriori, ou o setor de História tem alguma singularidade em relação às demais disciplinas que compunham o novo constructo. ${ }^{1}$ Por outro lado, também seria o caso de inquirir a respeito das motivações e rendimentos das investidas, sobretudo de Eurípedes, em alocar-se em posições de poder institucional: direção da FFCL-USP, representação da Congregação da Faculdade no Conselho Universitário ( $\mathrm{CO}$ ), entre outras. Ainda que os textos oficiais de estabelecimento da instituição afirmem e reafirmem que um de seus propósitos consistia em formar professores, sabe-se que a profissionalização da docência foi um processo lento, repleto de disputas, e que os primeiros formados da FFCL-USP não tinham posto certo, seja no ensino público, seja no privado. ${ }^{2} \mathrm{~A}$ leitura atenta do que Eurípedes escreveu sugere fortemente que uma de suas preocupações consistia em trabalhar para construir as condições de trabalho para os alunos que formava - fossem eles ocupar postos na Educação Básica ou Superior. Para dar apenas um exemplo: na aula inaugural de 15 de março de 1949, ele reclamava de verbas, de instalações e do mercado profissional que os 
egressos não encontravam à época, receando perder talentos (PAULA 1953, p. 157 e ss.). Dito de outro modo: o padrão de relação entre ensino universitário de História e os demais níveis de ensino não correspondia ao atual. Isto é, estava destituído de dinâmica própria e auto propulsora, visto que o sistema educacional estava em processo de formação, sendo, portanto, mais dependente da ação dos agentes em posições estratégicas. É quase o oposto o que se constata nos dias atuais, quando a dinâmica sistêmica tendencialmente absorve a todos - mesmo estando em posições de poder institucional. Trata-se de uma evidência banal, mas ela nem sempre conduz a análise. ${ }^{3}$ Ademais, embora seja um assunto para investigar, é possível interrogar: a direção institucional de suas investidas não teve incidência em sua produção intelectual? Exemplos de outros contextos assinalam as (im)possibilidades, assim como a dinâmica temporal envolvida no acúmulo simultâneo ou sucessivo dos poderes especificamente intelectuais e daqueles especificamente institucionais (BOURDIEU 1984, p. 138 e ss. ). ${ }^{4}$ Como explicar a imensa produção de textos para a Revista de História pari passu à exígua produção de pesquisa à luz das dificuldades em relação à documentação na área de História Antiga (que o historiador procurava sanar com suas viagens ao exterior)? O retrato que Eduardo D'Oliveira França desenha de Eurípedes - com quem travou amizade na Faculdade de Direito do Largo São Francisco e com quem lutou na Revolução Constitucionalista de 1932 -, então recém-falecido, afirmando que sua "vida (foi) gasta para atapetar a vida dos outros" (FRANÇA 1977) ganha um sentido dramático e ambíguo. Ele parece desvalorizá-lo intelectualmente para melhor enaltecê-lo institucionalmente.

Astransferênciasculturais na historiografia brasileira élivro indiscutivelmente incontornável para quem se interessa pela recepção dos Annales no Brasil. Do mesmo modo, é imprescindível para a inteligibilidade dessas trocas culturais que o pesquisador entrelace os vestígios concernentes ao período em que Fernand Braudel lecionou na FFCL-USP (1935-1937). Ora, lê-los cautelosamente pode suscitar novos nexos entre evidências antigas. Teria sido nesse período e por meio de suas aulas e palestras que o programa (total ou parcial, a investigar) dos Annales foi incorporado por seus ouvintes? Nessa direção, seria o caso de se ler com atenção o trecho de uma entrevista dada pelo historiador na ocasião da comemoração dos cinquenta anos da fundação da Universidade de São Paulo:

a política estava sempre presente. Quando terminavam as aulas, políticos, representantes do governador, lá chegavam e procuravam discutir com o Júlio de Mesquita Filho quem estava lá [...] não escondiam uma certa preocupação de ver que estávamos formando intelectuais novos recrutados num nível relativamente modesto (BRAUDEL 1984).

Se for possível o paralelo de duas relações: professores e alunos / pintores e clientela, o cenário fica repleto de conflitos. A declaração sugere que as elites

\footnotetext{
3 Uma proposta oposta a esta reconstitui os liames da hierarquia do sistema de ensino para conferir inteligibilidade às condições e obstáculos da produção inovadora dos antiquisants franceses. A leitura dá o que pensar a respeito de nossa experiência (BENTHIEN 2011, p. 61 e ss.).

${ }^{4}$ Recém-traduzido por Ione Ribeiro Valle e Nilton Valle para a língua portuguesa sob o título Homo academicus e publicado pela editora da UFSC em 2011.
} 
contratantes impuseram algum freio às aulas, às inovações - eram elas afinal que financiavam missionários franceses e aulas de História. É difícil supor a existência da autonomia do "campo científico" nesse cenário.

As indagações sugeridas pressupõem, com efeito, outro modus operandi de manejar a bibliografia de referência. O leitor atento nota que há, no modo como a interpelam, se não um esforço para conciliar divergências em detrimento de expor discordâncias, decerto uma tendência para não apostar nelas. E, nesse regime de interlocução, uma referência se liga à outra e a documentação as confirma. A vantagem é indiscutível: os autores não despendem energias com controvérsias irrelevantes ou falsos problemas. Deixam, no entanto, de formular algumas que valeria a pena desenvolver. Por exemplo, para aludir a Lucien Febvre e seu Rabelais: "Se 'Braudel já fosse Braudel', ao chegar ao Brasil, seria possível a tal 'inovação' dos Annales, em São Paulo, na década de 1930?".

Em suma, talvez por essa relação apaziguada com a bibliografia e contida em relação ao próprio escopo, os autores atiçam a reflexão sobre o assunto e deixam, contudo, seus leitores inquietos. Por um lado, esse comedimento, em tempos como os atuais, em que o alvoroço por destaque fácil seduz inteligências, é de se apreciar. Por outro lado, esquivam-se de controvérsias. O resenhista fica assim numa posição difícil e tentado a indagar, mais diretamente: "farta bibliografia, farta documentação. Mas a presença dos historiadores franceses das missões em tela garantiu a presença da historiografia dos Annales? Em São Paulo? No Brasil?". O assunto está longe de ser esgotado.

\section{Referências bibliográficas}

BENTHIEN, Rafael Faraco. Interdisciplinaridades: latinistas, helenistas e sociólogos em revista (França, 1898-1920). Tese (Doutorado em História Social) Programa de Pós-Graduação em História Social, Faculdade de Filosofia, Letras e Ciências Humanas, Universidade de São Paulo, São Paulo, 2011.

BOURDIEU, Pierre. Homo academicus. Paris: Minuit, 1984.

A comparabilidade dos sistemas de ensino. In: DURAND, J. C. Educação

e hegemonia de classe. Rio de Janeiro: Zahar Editores, 1979.

BRAUDEL, Fernand. Entrevista. Jornal da Tarde,1984.

CHARLE, Christophe. Como anda a história social das elites e da burguesia? In: HEINZ, Flávio M. (org.). Por outra história das elites. Rio de Janeiro: Editora FGV, 2006.

FRANÇA, Eduardo D'Oliveira. Homenagem da Congregação à Memória do Prof. Dr. Eurípedes Simões de Paula. Separata. São Paulo: FFLCH-USP, 1977.

FREITAS, Itamar. Histórias do ensino de história no Brasil (1890-1945). São Cristóvão, UFS; Aracaju: Fundação Oviêdo Teixeira, 2006.

MARCÍlIO, Maria Luíza. História da escola em São Paulo e no Brasil. São Paulo: Imprensa Oficial; Instituto Fernand Braudel, 2005. 
NOIRIEL, Gérard. Naissance du métier d'historien. Genèses, n. 1, p. 58-85, 1990.

PAULA, Eurípedes Simões. A História e seu ensino na Faculdade (15/03/1949). Anuário da Faculdade de Filosofia, Ciências e Letras da USP. 19391949. São Paulo: Seção de Publicações, 1953.

RODRIGUES, Lidiane Soares. A produção social do marxismo universitário: mestres, discípulos e um seminário. Tese (Doutorado em História Social) Programa de Pós-Graduação em História Social, Faculdade de Filosofia, Letras e Ciências Humanas, Universidade de São Paulo, São Paulo, 2012.

ROIZ, Diogo da Silva; SANTOS, Jonas Rafael. As transferências culturais na historiografia brasileira: leituras e apropriações do movimento dos Annales no Brasil. Jundiaí: Paco Editorial, 2012.

PEIXOTO, Fernanda. Estrangeiros no Brasil: a Missão Francesa na Universidade de São Paulo. Dissertação (Mestrado em Antropologia Social Programa de Pós-Graduação em Antropologia Social Universidade Estadual de Campinas, Campinas, 1991. 